\title{
Conjugate Heat Transfer Study at Interior Surface of NGV Leading Edge with Combined Shower Head and Impingement Cooling
}

\author{
Arun Kumar Pujari, B. V. S. S. S. Prasad, and N. Sitaram \\ Thermal Turbomachines Laboratory, Department of Mechanical Engineering, Indian Institute of Technology Madras, \\ Chennai 600036, India \\ Correspondence should be addressed to Arun Kumar Pujari; akp327@gmail.com
}

Received 26 May 2014; Revised 9 August 2014; Accepted 11 August 2014; Published 1 October 2014

Academic Editor: J-C. Han

Copyright (C) 2014 Arun Kumar Pujari et al. This is an open access article distributed under the Creative Commons Attribution License, which permits unrestricted use, distribution, and reproduction in any medium, provided the original work is properly cited.

\begin{abstract}
A computational study on conjugate heat transfer is carried out to present the behavior of nondimensional temperature and heat transfer coefficient of a Nozzle Guide Vane (NGV) leading edge. Reynolds number of both mainstream flow and coolant impinging jets are varied. The NGV has five rows of film cooling holes arranged in shower head manner and four rows of impingement holes arranged in staggered manner. The results are presented by considering materials of different thermal conductivity. The results show that the mainstream flow affects the temperature distribution on the interior side of the vane leading edge for high conductivity material whereas it has negligible effects for low conductivity material. The effect of changing blowing ratio on internal heat transfer coefficient and internal surface temperature is also presented.
\end{abstract}

\section{Introduction}

The leading edge of a gas turbine nozzle guide vane is subjected to high thermal load; hence combined film cooling and impingement cooling is adopted for high heat transfer rates. The impinging jets after striking the blade interior surface comes out through the film cooling holes and makes a layer over the blade surface and prevents it from hot mainstream.

Most of the previous literature focused on jet impingement on curved surface by varying parameters such as hole configuration, target plate distance to jet diameter ratio, and the jet Reynolds number variation at constant temperature or at constant heat flux boundary condition without considering the mainstream flow effect. Probably the first investigations on air jet impingement with film cooling holes were reported by Hollworth et al. [1, 2]. They considered flat plate jet impingement with same diameter effusion holes. They found an increase of $35 \%$ in heat transfer rate with an array of staggered film holes in comparison with the case without film holes. Cho and Rhee [3] reported heat and mass transfer result for multiple jet impingement on flat surface and exiting through the effusion holes. They found higher heat transfer coefficient distribution near the up-wash region. Ekkad et al. [4] conducted experiment on flat plate with effusion holes by considering three different exit flow configurations: in the first configuration flow exits along the same direction of entry; in the second case flow exits in opposite direction of entry; and in the third one flow exits in both the directions. They observed significant variations in heat transfer coefficient distribution in each case because of cross flow effect. Metzger et al. [5] showed that the circular jet impinging on a concave surface would produce higher heat transfer coefficient than the comparable twodimensional jets impinge on a plane surface. Thomann [6] quantified the heat transfer to be about twenty percent higher on the concave surface than on the flat surface. Tabakoff and Clevenger [7] conducted experimental investigations for multiple jets impinging on the concave surface for two exit configurations: (i) side edges are blocked and both top edges are open and (ii) side edges and one of the top edges are blocked. They found that by closing one side the heat transfer 
performance did not alter much. Bunker and Metzger [8, 9] noted that the flow extraction showed only a small influence on heat transfer. They also pointed out that the jets in line with film holes would yield higher heat transfer coefficient than when they are in staggered configuration. Ramakumar and Prasad $[10,11]$ demonstrated that $\kappa-\omega$ SST model predicts the heat transfer characteristics more closely with the experimental data on concave surface with multiple impinging jets. Kumar and Prasad [12] computationally investigated jet impingement with constant Reynolds number on concave surface with multiple rows of impinging jets and effusion holes for (a) staggered and inline arrangement of effusion holes and (b) four numbers of exit configurations for a height to diameter ratio of unity. Panda and Prasad [13] have compared the effectiveness values for film cooling and the combined impingement and film cooling on a flat plate and concluded that the surfaces with combined cooling are higher as well as more uniform. Li et al. [14] have studied the effect of arrangement of film holes on impingement heat transfer and concluded that the hole position of film cooling holes significantly affects the shape of high heat transfer area and $\mathrm{Nu}$ in stagnation zone decreases with the increase of array angle of film cooling holes. Jordan et al. [15] have found out that the addition of fillets at the edges of the jet orifice and the introduction of significant cross flow velocity at the inlet of the jet can significantly degrade the cooling characteristics on the leading edge of the turbine blade. Mehendale and Han [16] used a cylindrical model with two rows of film holes for studying the effect of Reynolds number and film hole spacing on the adiabatic effectiveness. They found an increase in effectiveness value with increase in Reynolds number. Heidmann et al. [17] developed a conjugate heat transfer solver and applied to a realistic film-cooled turbine vane with two blade materials: (i) a high thermal conductivity Inconel nickel-based alloy and (ii) low thermal conductivity silicon nitride ceramic. They found that the conjugate heat transfer calculations generally yield a lower outer wall temperature in comparison with the conventional adiabatic estimates. Lau et al. [18], Gau et al. [19] and Montomoli et al. [20] conducted investigations for internally cooled passages and reported the effect of thermal conductivity. In [20] for instance, they showed that thermal gradients in the high pressure gradient nozzle are reduced by using high conductivity materials and suggested usage of nickel-aluminide alloys $(k=69 \mathrm{~W} / \mathrm{mK})$ to reduce thermal gradients by 3 to 4 times compared to current design practice.

From the above literature survey it is found that the effect of variation of both mainstream flow and jet impingement flow on vane internal surface under conjugate boundary condition has not been reported yet. The mainstream flow variations lead to change in coolant flow distribution over the external surface which leads to change in internal surface temperature and flow structure. The presence of different temperature fluids on the external and internal side of the vane and the conductivity of the vane surface makes the problem more conjugate in nature. This paper presents variation heat transfer coefficient distribution on the internal surface with the mainstream Reynolds number and the jet Reynolds number varied simultaneously for the leading edge of a nozzle guide vane. The study is performed by varying the blowing ratio $\left(M=\rho_{c} V_{c} / \rho_{m} V_{m}\right)$ with $M=1, M=1.5$ and $M=2$. In each case three different mainstream velocities and jet velocity are varied to get constant blowing ratio.

\section{Methodology}

2.1. Physical and Computational Models. The computational domain is two-dimensional cascade sections with two passages, maintaining a space chord ratio of 0.88 as shown in Figure 1(a). The domain is extended 1.5 chord upstream and downstream of the blades. The leading edge region of a high pressure turbine inlet guide vane is simulated computationally by considering a curved plate having a radius of curvature of $21 \mathrm{~mm}$ and thickness of $5 \mathrm{~mm}$ provided with five rows of $2.85 \mathrm{~mm}$ diameter staggered shower head holes as shown in Figure 1(b). The leading edge inner surface which is the target surface is shown in Figure 1(c). The film holes are arranged in such a way that the middle row of holes is at stagnation region and the other four rows are positioned at $\pm 30^{\circ}$ and $\pm 60^{\circ}$ with respect to the middle row. Typically the film holes of a gas turbine NGV are inclined in the span wise direction from $55^{\circ}$ to $0^{\circ}$ in each row. The coolant is supplied through 4 rows of round impinging jets having diameter $2.5 \mathrm{~mm}$ arranged in staggered fashion in such a way that each alternate row contains 15 (jet row 2 and 4) and 16 (jet row 1 and 3) numbers of circular round jets impinging on the concave shaped leading edge internal surface. The arrangement of film cooling holes and impingement holes is shown in Figure 2. The distance between the target surface and impingement holes is $2.8 \mathrm{~mm}$ which gives $\mathrm{H} / \mathrm{d}$ (ratio of target plate distance to jet diameter) of 1.12 .

The computational model consists of two fluid zones and a solid zone. Fluid zone 1 is the mainstream flow and fluid zone 2 is the coolant flow from impingement holes to the vane rear surface and through the film cooling holes to mix finally with fluid zone 1 . The solid zone comprises the leading edge region. Mesh is generated in these zones by grid generating tool Ansys ICEM CFD. The mesh of computational domain along with the leading edge mesh is shown in Figures 3(a) and 3(b). Grid independence study is conducted with three meshes: coarse, medium, and fine, which had approximately 1.7 million, 2.54 million, and 3.1 million cells, respectively. The average nondimensional temperature $\left[\theta=\left(T-T_{c}\right) /\left(T_{m}-T_{c}\right)\right]$ is presented along the curvature of the inner surface on which the jet is impinging, for all three meshes as shown in Figure 4. The medium mesh is found optimum for the present study as the result was almost independent of further grid refinement. A multi block technique is made use of which allows to create separate grids for different parts of the flow domain. The mesh in the impingement holes, film holes, and the solid leading edge are tetrahedral and refined whereas the flow domain is hexahedral meshed. A three-dimensional boundary layer with first row height of $0.02 \mathrm{~mm}$ and growth factor of 1.2 for 20 rows is provided throughout over the blade surface and over the film hole exits to bring down the $y+$ value of 1st cell below 1 . 


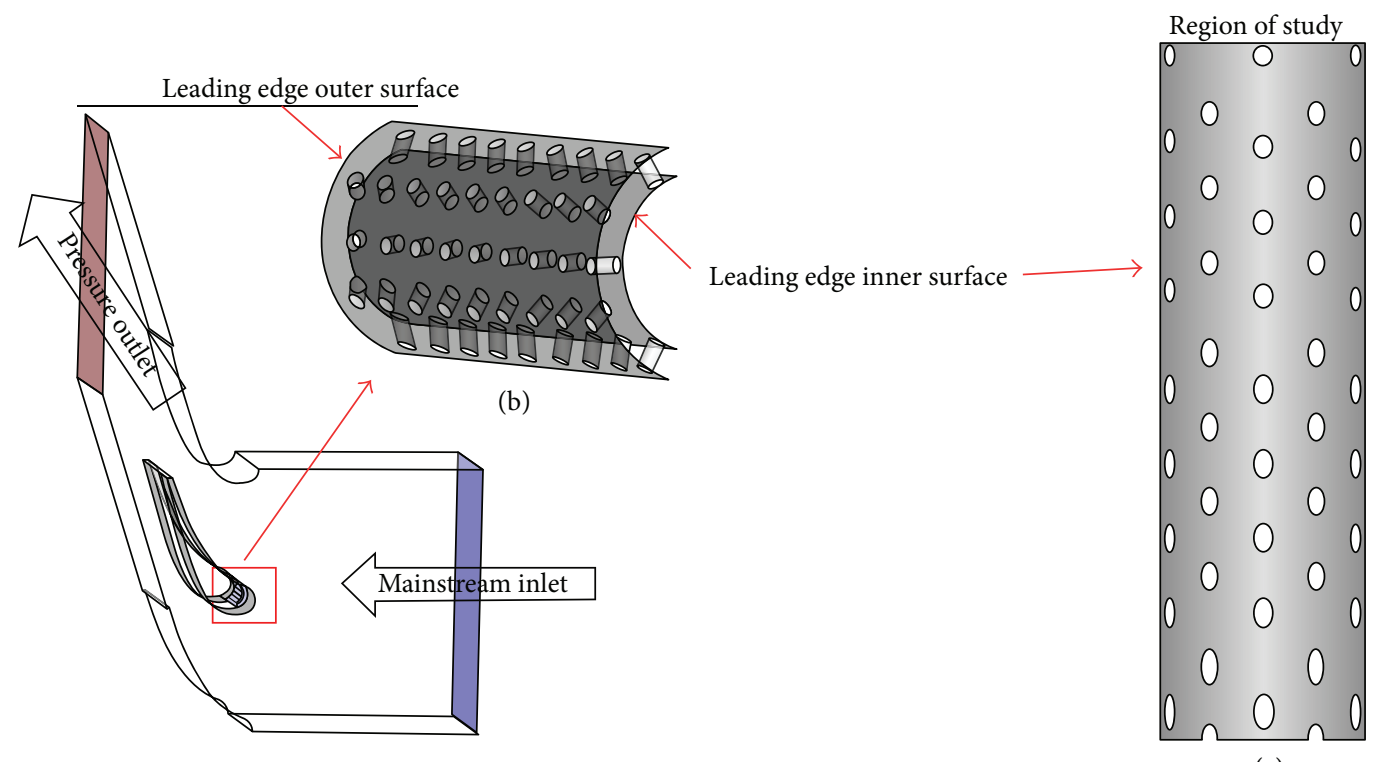

(a)

(c)

FIgure 1: (a) Cascade domain. (b) Leading edge outer and inner surface. (c) Region of study.

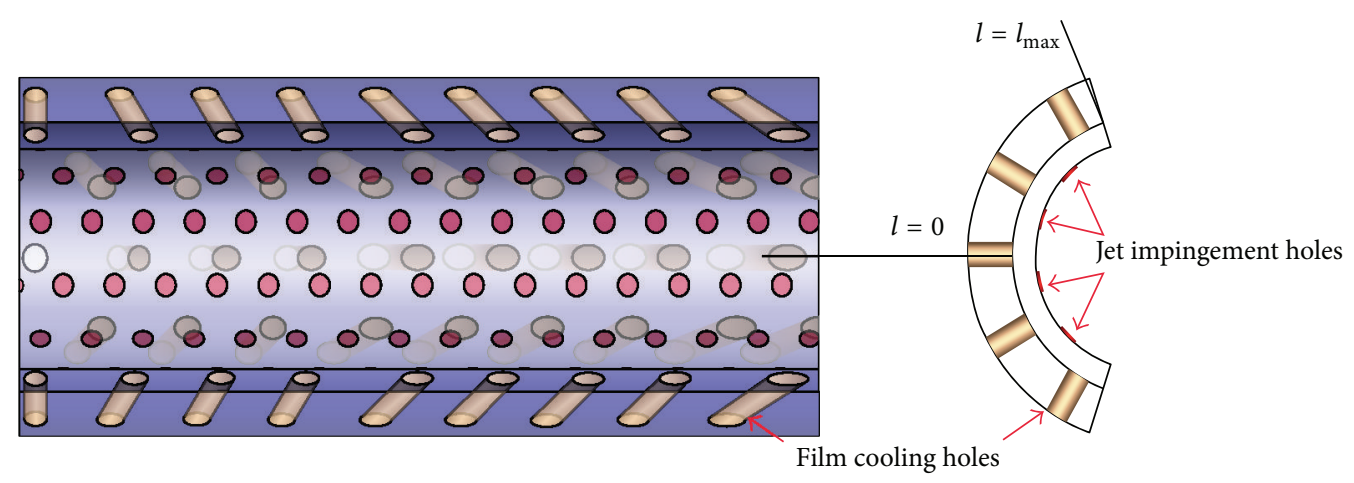

FIGURE 2: Leading edge film cooling holes and impingement holes arrangement.

At the cascade domain inlet and impingement holes inlet, a uniform velocity and temperature boundary condition is specified for the mainstream flow and coolant flow, respectively. The coolant from the inlet impinges on the rear side of the leading edge and then effuses out of the film (shower head) holes to interact with the mainstream and finally exits the domain through a constant pressure outlet. A turbulent intensity of $1 \%$ is imposed at the mainstream inlet and 5\% at the impingement inlet. A periodic boundary condition is given at the top and bottom wall of the domain so as to generate an infinite cascade model. The coolant and mainstream temperature are maintained constant at $288 \mathrm{~K}$ and $308 \mathrm{~K}$, respectively. SST $k-\omega$ turbulence model is used for computations. Conjugate effects are investigated for materials of different conductivity of the blade.

2.2. Numerical Solution. Formulation of three-dimensional conjugate heat transfer problem is done with the following assumptions: (i) the fluid is incompressible, (ii) the fluid properties are constant, (iii) radiation and natural convection are neglected, (iv) viscous dissipation is absent, and (v) the flow is steady. The governing equations used for simulation are the Reynolds averaged continuity, momentum, and the energy equations along with the equations for modeling the turbulence quantities. Boundary conditions used for the present study are as follows:

(i) no slip boundary condition at wall, $V_{w}=0$;

(ii) mainstream inlet temperature $T_{m}=308 \mathrm{~K}$, coolant temperature $T_{c}=288 \mathrm{~K}$;

(iii) coolant inlet condition, $V_{c}$ calculated from blowing ratio;

(iv) outlet boundary condition, $P=P_{\mathrm{amb}}$ at exit;

(v) conjugate boundary condition at solid plate, $T_{s}=T_{f}$, $k_{s}\left(\partial T_{s} / \partial y\right)=k_{f}\left(\partial T_{f} / \partial y\right)$ at leading edge walls.

Governing equations are solved using a finite volume based Fluent14 solver from the Ansys14 package. The $\kappa-\omega$ SST model is adopted for turbulence modeling. Standard pressure interpolation scheme is used. SIMPLE algorithm is 


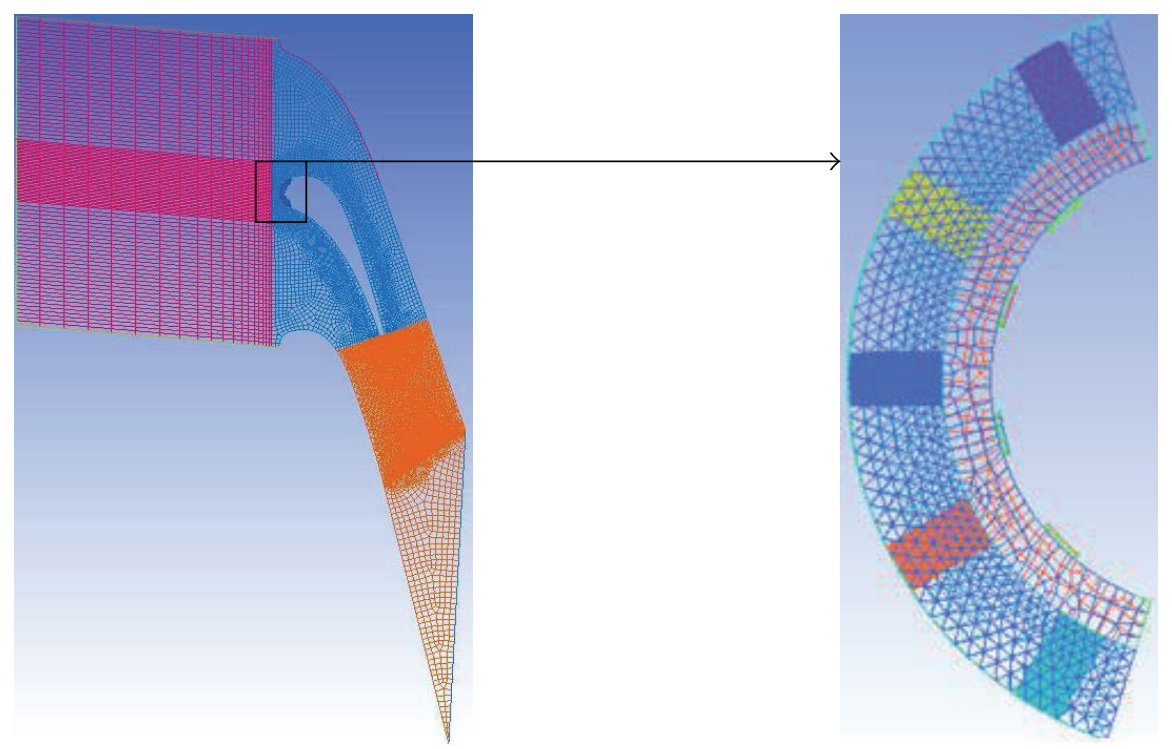

(a)

(b)

Figure 3: (a) Cascade domain mesh. (b) Leading edge mesh.

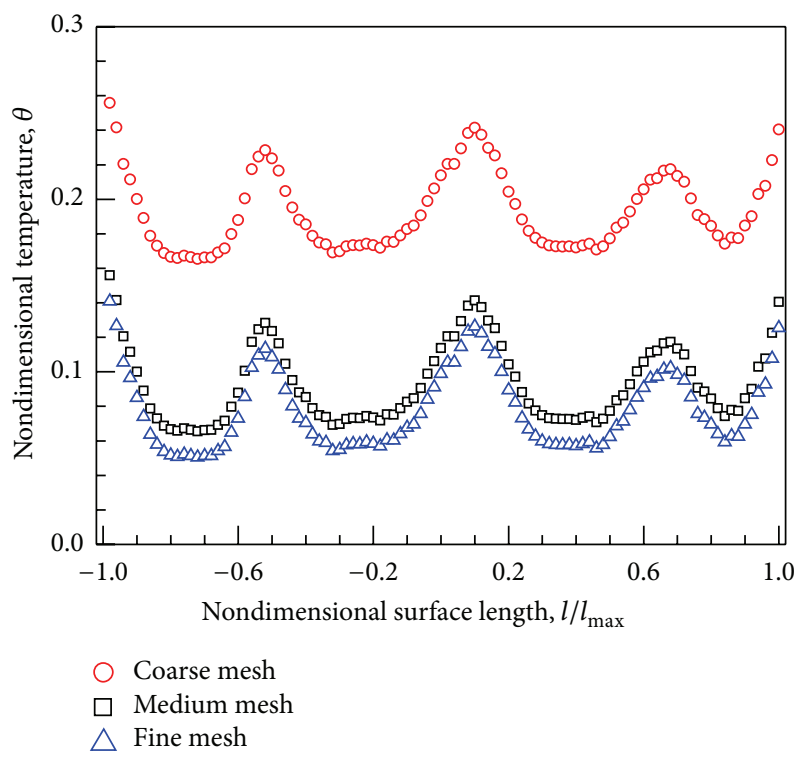

FIGURE 4: Dimensionless temperature for three different grids.

used for pressure-velocity coupling. Second order upwind scheme is used for momentum and energy and first order upwind scheme for $\kappa$ and $\omega$. The solution is considered to be converged when the maximum residual value is in the order of $10^{-5}$ for continuity, momentum, and turbulence equations and $10^{-6}$ for energy equation. Further, an area weighted average of dimensionless temperature at isosurfaces in the spanwise direction is constantly monitored, so that the variation will be within $0.1 \%$ for 500 consecutive iterations. For the present study, two materials having thermal conductivity $k=14.9 \mathrm{~W} / \mathrm{mK}$ (SS-Stainless Steel) and $k=0.2 \mathrm{~W} / \mathrm{mK}$ (PP-Perspex) are considered for conjugate calculation. Table 1 shows how the jet velocity and mainstream velocity are varied to maintain constant blowing ratio.

\subsection{Validation}

2.3.1. Static Pressure Validation. The SST $\kappa-\omega$ turbulence model is validated with the static pressure experiments conducted in the laboratory. The experimental setup consists of a cascade of five numbers of blades. The same boundary conditions are maintained for both experiment and computation. In Figure 5 the experimental and computational data are compared and good correspondence is seen between the static pressure distributions around the whole blade, thereby validating the mesh and the model used in the computations.

2.3.2. Temperature Validation. To know the accuracy of the chosen SST $k-\omega$ turbulence model the thermal parameter "temperature" is also considered for validation. Some preliminary experiments are conducted on the same vane profile in a two-dimensional linear cascade. The experimental setup consists of a cascade of five number of blades made of up transparent Perspex. The internal surface temperature measurement is carried out by putting Thermochromic Liquid Crystal sheets. The same boundary conditions are maintained for both experiment and computation. The color change is recorded by using a high definition camcorder and later processed in MATLAB to obtain the surface temperature. The data reduction is done by drawing a line across the span of the vane as shown in Figure 6. The temperature data are picked at regular interval along the line to compare with the computational result. The difference between the computational and experimental values is usually within $5 \%$ except for one point, where the difference is about $18 \%$. 
TABLE 1: Parameters varied.

\begin{tabular}{|c|c|c|c|c|c|}
\hline Blowing ratio $(M)$ & Case number & $\begin{array}{l}\text { Mainstream velocity } \\
(\mathrm{m} / \mathrm{s})\end{array}$ & $\begin{array}{c}\text { Mainstream } \\
\text { Re }\end{array}$ & $\begin{array}{l}\text { Jet velocity } \\
(\mathrm{m} / \mathrm{s})\end{array}$ & Jet $\operatorname{Re}$ \\
\hline \multirow{3}{*}{$M=1$} & M1 Rel & 10 & 139516 & 8.5 & 1450 \\
\hline & M1 Re2 & 20 & 279033 & 17.0 & 2889 \\
\hline & M1 Re3 & 30 & 418550 & 25.5 & 4350 \\
\hline \multirow{3}{*}{$M=1.5$} & M1.5 Rel & 10 & 139516 & 12.7 & 2174 \\
\hline & M1.5 Re2 & 20 & 279033 & 25.5 & 4350 \\
\hline & M1.5 Re3 & 30 & 418550 & 38.3 & 6523 \\
\hline \multirow{3}{*}{$M=2$} & M2 Re1 & 10 & 139516 & 16.9 & 2887 \\
\hline & M2 Re2 & 20 & 279033 & 33.9 & 5789 \\
\hline & M2 Re3 & 30 & 418550 & 51.0 & 8701 \\
\hline
\end{tabular}

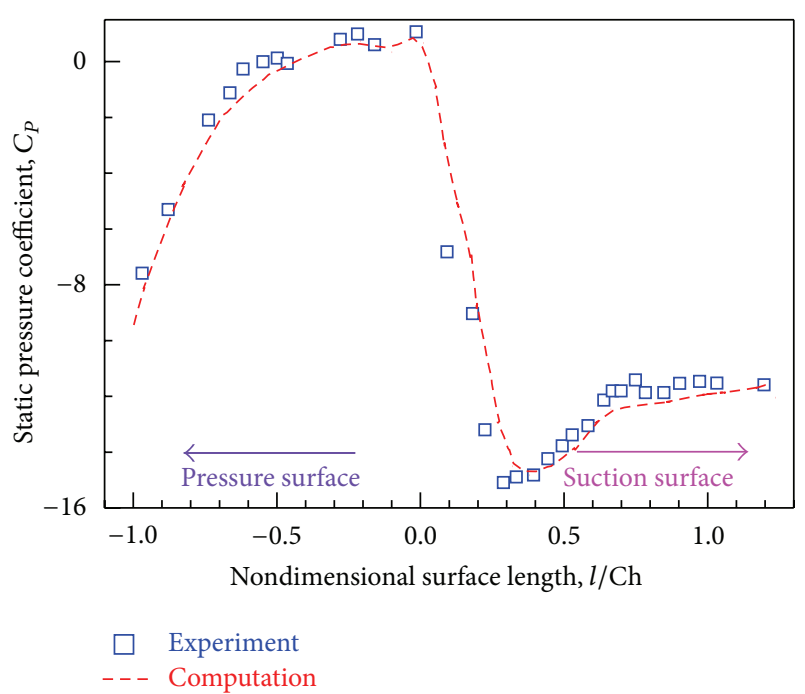

FIGURE 5: Validation of present methodology: static pressure.

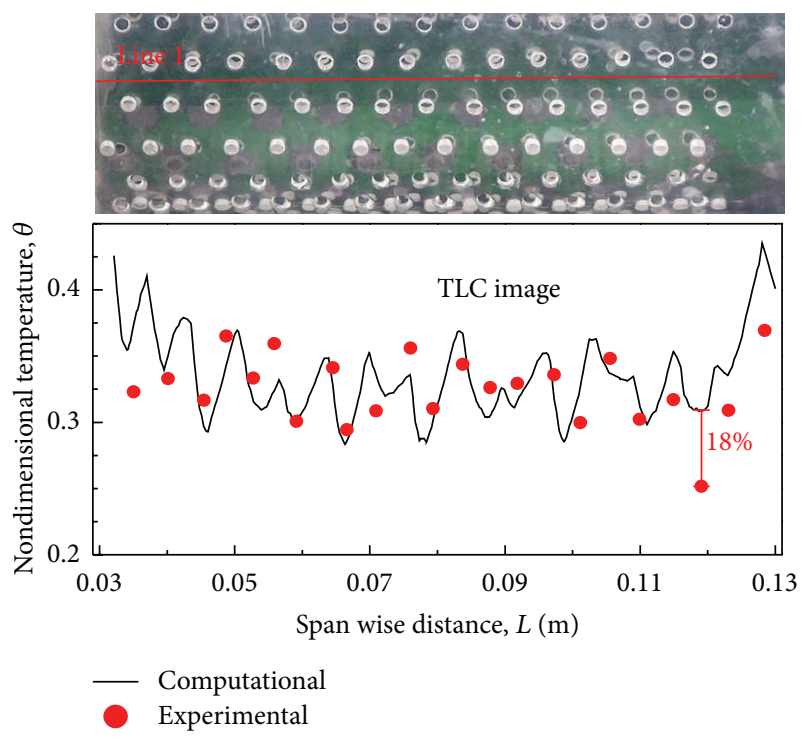

FIGURE 6: Validation of present methodology: temperature.

\section{Results and Discussion}

3.1. Effect of Mainstream and Jet Reynolds Numbers.

The parameters investigated in this study are summarized in the following three categories:

(i) effect of variation of mainstream Reynolds number with constant jet Reynolds number;

(ii) constant mainstream Reynolds number with variation in jet Reynolds number;

(iii) simultaneous variation of both jet Reynolds number and mainstream Reynolds number (constant blowing ratio)

To know the effect of conjugate heat transfer the nondimensional temperature values are analyzed for both Perspex and stainless steel. The parameters that are kept constant are $\mathrm{H} / \mathrm{d}$ (target plate distance to jet diameter ratio) of 1.12 . The data is reduced by drawing number of lines on the interior surface as shown in Figure 7. The values of heat transfer coefficient and nondimensional temperature is averaged along these lines. The stagnation line is represented by 0 ; the end line on the suction surface corresponds to +1 whereas the end line on the pressure surface corresponds to -1 .

3.1.1. Effect of Variation of Mainstream Reynolds Number Keeping the Jet Reynolds Number Constant. In this case the jet Reynolds number is maintained constant at 4350 whereas the mainstream Reynolds number is varied for two different mainstream velocities of $20 \mathrm{~m} / \mathrm{s}$ and $30 \mathrm{~m} / \mathrm{s}$. The blowing ratio is changed from 1 to 1.5 as the mainstream Reynolds number is changing:

Case: M1 Re3 mainstream Reynolds number $=418550$ $(30 \mathrm{~m} / \mathrm{s})$, jet Reynolds number $=4350(25.5 \mathrm{~m} / \mathrm{s})$;

Case: M1.5 Re2 mainstream Reynolds number $=279033$ $(20 \mathrm{~m} / \mathrm{s})$, jet Reynolds number $=4350(25.5 \mathrm{~m} / \mathrm{s})$.

The area weighted average of heat transfer coefficient and nondimensional temperature are presented for stainless steel (SS) and Perspex (PP) in Figures 8 and 9, respectively. The mainstream Reynolds number though nearly doubled but it has no effect on the heat transfer coefficient distribution 


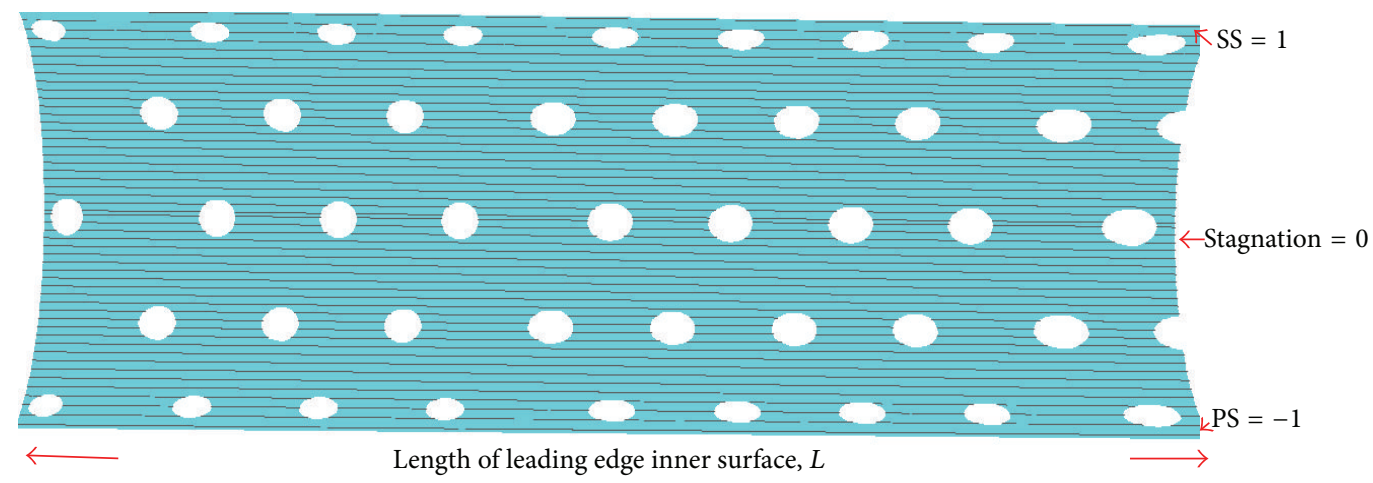

FIGURE 7: Lines on the impinging target surface for data reduction.

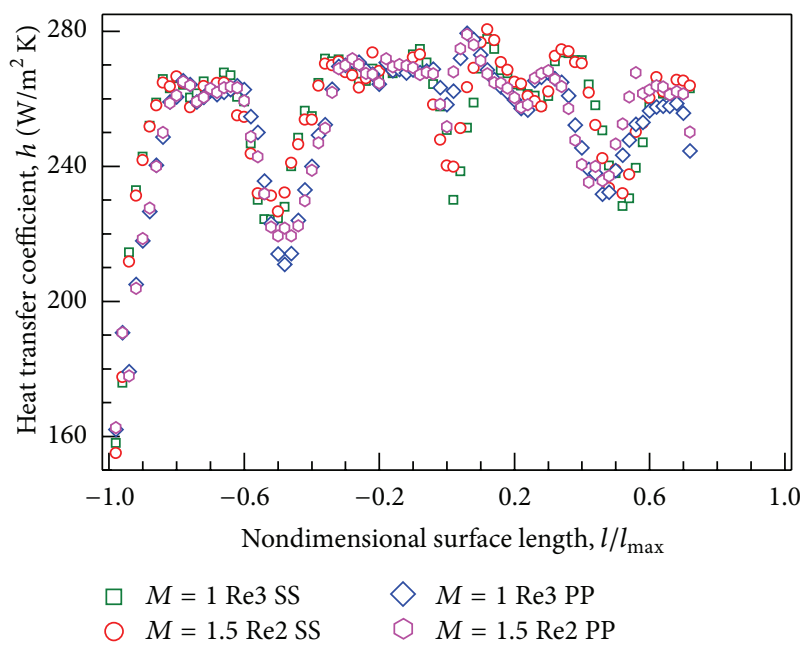

FIGURE 8: Effect of variation of mainstream Reynolds number on heat transfer coefficient.

on the inner surface under conjugate boundary condition. The conductivity of the material also does not have much influence on the heat transfer coefficient distribution. It is found the variation in average heat transfer coefficient between cases M1 and M1.5 for both stainless steel and Perspex is found to be less than 2\%. In Figure 9 the nondimensional temperature distribution is presented for both SS and PP material. It is found that for PP, between cases M1 Re3 and M1.5 Re2, the average nondimensional internal surface temperature difference is less than $3 \%$, which indicates for low conductivity material the internal surface temperature is independent of external mainstream Reynolds number. When the mainstream velocity is increased from $20 \mathrm{~m} / \mathrm{s}$ to $30 \mathrm{~m} / \mathrm{s}$ the average nondimensional internal surface temperature of high conductivity material (SS) is increased by $10 \%$. From Figure 9 by comparing cases M1 Re3 SS and M1 Re3 PP it is noticed that the internal surface of higher conductivity material attains an average surface temperature $22 \%$ higher than the low conductivity material when a temperature gradient of $20^{\circ}$ centigrade is imposed between the mainstream and coolant.

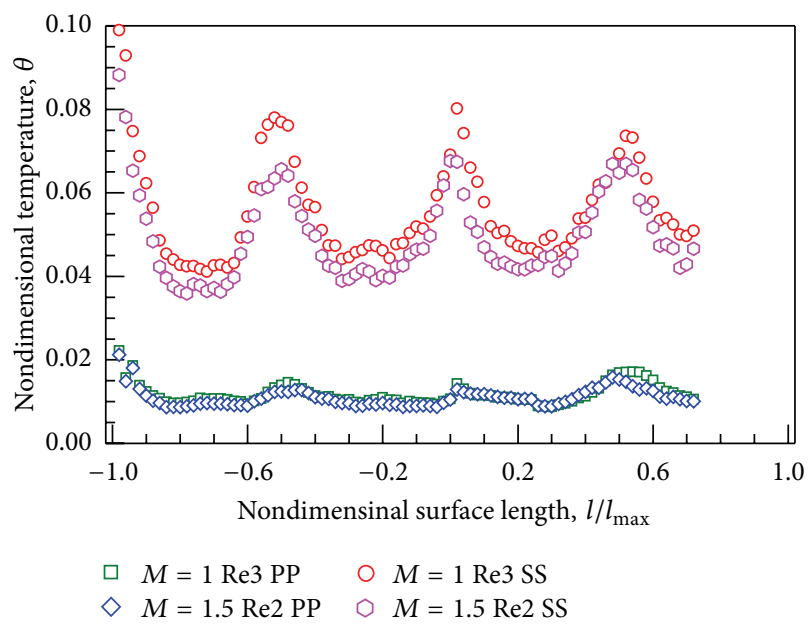

FIGURE 9: Effect of variation of mainstream Reynolds number on nondimensional temperature.

3.1.2. Constant Mainstream Reynolds Number with Variation in Jet Reynolds Number. For the present case the mainstream Reynolds number is kept constant and jet Reynolds number is increased as given below:

Case: M1 Rel mainstream Reynolds number = 139516 $(10 \mathrm{~m} / \mathrm{s})$, jet Reynolds number $=1450(8.5 \mathrm{~m} / \mathrm{s})$;

Case: M1.5 Rel mainstream Reynolds number $=139516$ $(10 \mathrm{~m} / \mathrm{s})$, jet Reynolds number $=2174(12.7 \mathrm{~m} / \mathrm{s})$;

Case: M2 Re1 mainstream Reynolds number $=139516$ $(10 \mathrm{~m} / \mathrm{s})$, jet Reynolds number $=2887(16.9 \mathrm{~m} / \mathrm{s})$.

The heat transfer coefficient variation is presented for the present case in Figure 10. It is observed that when the jet velocity increased by nearly $50 \%(8.5 \mathrm{~m} / \mathrm{s}$ to $12.7 \mathrm{~m} / \mathrm{s})$, the corresponding increase in average heat transfer coefficient (htc) is approximately $10 \%$. Similarly by comparing cases M1 Rel and M2 Rel where the jet velocity is nearly doubled the average heat transfer coefficient increase is approximately $20 \%$. For all the three cases, as the jet Reynolds number increases it is observed that along the jet impinging region there is drastic increase in heat transfer coefficient because of 


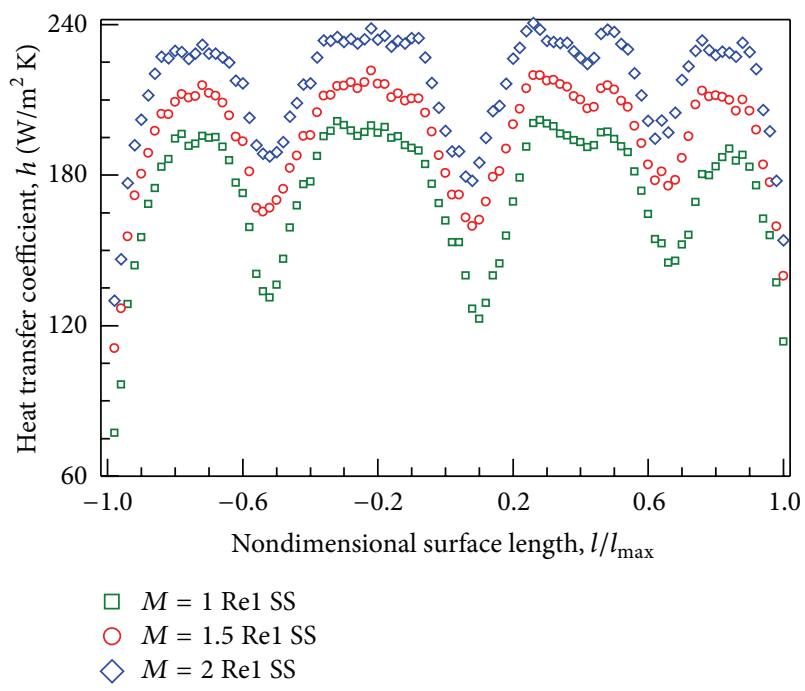

FIGURE 10: Effect of jet Reynolds number on heat transfer coefficient at constant mainstream Reynolds number.

impinging effect. Similar trend is observed for low conductivity material. As the variation of heat transfer coefficient is less for SS and PP, the heat transfer coefficient results for PP are not discussed further.

The nondimensional temperature distributions for all the 9 cases are compared for the high conductivity material in Figures 11(a), 11(b), and 11(c). In Figure 11(a) the mainstream Reynolds number is kept at 139516 and the jet Reynolds number is increased approximately by $50 \%$ (M1.5 Re1) than by $100 \%$ (M2 Re1); it is noticed that between the blowing ratios M1 Re1 and M1.5 Re1 the average dimensionless temperature of internal surface shows decrease of $11 \%$ which is obvious as jet Reynolds number is increased. However between blowing ratios M1.5 Rel and M2 Rel though the coolant jet Reynolds number is increased average internal surface temperature is increased by $8 \%$. The major cause of this peculiar trend is with increase in jet velocity jet lift off takes place at the exit film cooling holes as the mainstream Reynolds number is kept constant, which in turn reduces the film effectiveness at the external surface and higher temperature is observed on the external surface. The higher temperature distribution on the external surface leads to heat penetration on the internal surface for the higher conducting material. This peculiar trend also indicates that merely increase in jet Reynolds number may not be advantageous in case of combined impingement and shower head film cooling arrangements. From Figures 11(b) and 11(c) similar trend in nondimensional temperature is observed for the higher Reynolds number cases. It is noticed that between cases M1 Re 2 and M1.5 Re2, $4 \%$ decrease in average nondimensional surface temperature is observed whereas between cases M1.5 Re2 and M2 Re2, $1 \%$ increase in temperature is observed. For the third case (Figure 11(c)) between cases M1 Re3 and M1.5 Re3, 5\% decrease in average nondimensional surface temperature is observed whereas between cases M1.5 Re3 and M2 Re3, 1\% increase in temperature is observed. From the three figures
(Figures 11(a), 11(b), and 11(c)) it is observed that among all the cases the M1.5 Rel gives optimum averaged surface temperature distribution for moderate jet velocity $(12.7 \mathrm{~m} / \mathrm{s})$, whereas the case M2 Re3 shows lowest temperature (local variation) at the impingement locations because of highest jet Reynolds number (8701).

\subsubsection{Simultaneous Variation of Both Jet Reynolds Number} and Mainstream Reynolds Number (Constant Blowing Ratio). The blowing ratio $\left(M=\rho_{c} V_{c} / \rho_{m} V_{m}\right)$ in case of combined impingement and film cooling arrangement can be varied either by changing mainstream Reynolds number or by changing the jet Reynolds number. In the present study for a constant blowing ratio both jet Reynolds number and the mainstream Reynolds number are changed simultaneously. In Figure 12 all the nine cases for SS are presented so as to compare the effect of constant blowing ratio. When the blowing ratio is kept constant (say M1) by proportionate increasing in both mainstream Reynolds number and jet Reynolds number simultaneously (Re1, Re2, Re3), the case with lowest Reynolds number (i.e., Rel) gives lowest average surface temperature. This trend indicates the predominance effect of film cooling on the leading edge interior surface for higher conducting material. Among all the nine cases the case M1.5 Rel shows lowest average surface temperature for SS and the case M2 Re3 (highest jet Reynolds number) for PP. For the lower conducting material the effect of impingement cooling affects the internal surface temperature distribution considerably. From the graph it is also observed that the cases M1.5 Re3 (mainstream Reynolds number $=418550$ ) and M2 Re2 (279033) show extremely small difference in average internal surface temperature; the major cause of this trend is $33 \%$ decrease in mainstream velocity $(30 \mathrm{~m} / \mathrm{s}$ to $20 \mathrm{~m} / \mathrm{s})$ whereas the jet velocity is decreased only $11 \%(38.3 \mathrm{~m} / \mathrm{s}$ to $33.9 \mathrm{~m} / \mathrm{s}$ ). It shows that because of conjugate effect two different blowing ratios give the same averaged temperature distribution.

3.1.4. Contours of Temperature Distribution for Stainless Steel and Perspex. The arrangement of four jet impingement row (blue colored circle) along with vane leading edge inner surface is shown in Figure 13(a). In Figure 13(b) the static pressure distributions on the inner wall is presented for case M1 Rel, which shows higher pressure zones near the impingement zone and relatively lower pressure in area adjacent to the impinging jet area. It is observed from the pressure distribution contour that along the jet rows 1,2 , and 3 higher pressure region is identified whereas along jet row 4 the pressure values are relatively low because of lower pressure region created on the suction side film holes.

To know the qualitative effect of blowing ratio for both stainless steel and Perspex the temperature contours are shown in Figure 14. It is clear from the figures that stainless steel attained higher temperature because of its high conductivity and mainstream flow affecting considerably the interior of NGV leading edge whereas the low conductivity Perspex shows less sensitivity to the mainstream flow. The contours of temperature (for case M1 Rel) show that as the jet 


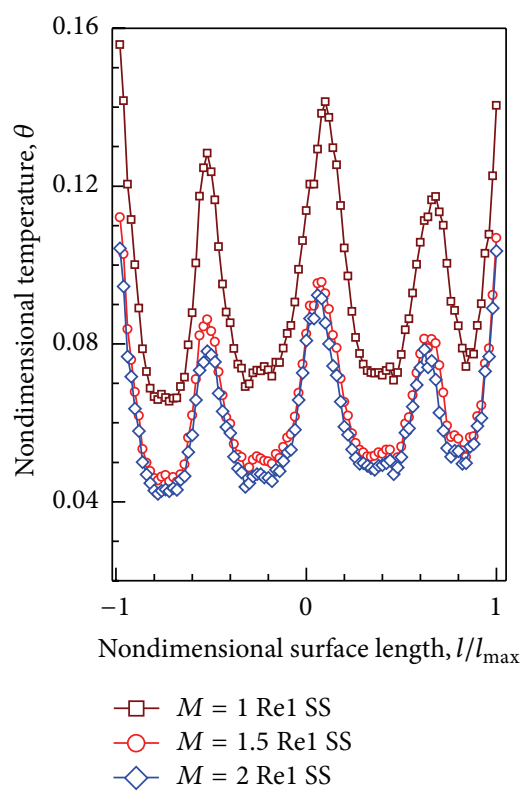

(a)

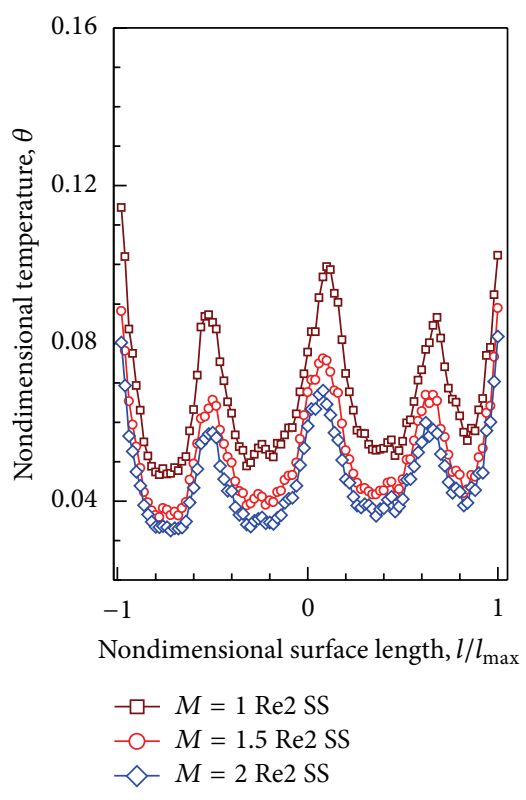

(b)

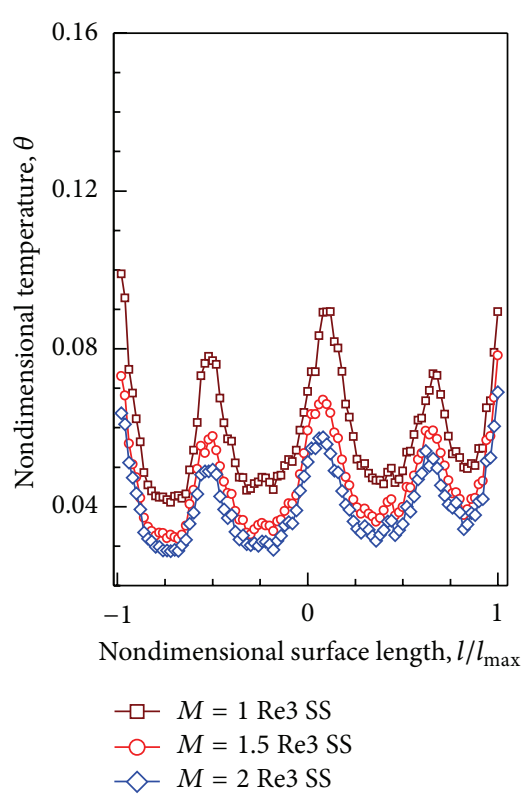

(c)

FIGURE 11: Effect of jet Reynolds number on nondimensional temperature at constant mainstream Reynolds number: (a) Re = 139516, (b) $\mathrm{Re}=279033$, and $(\mathrm{c}) \mathrm{Re}=41855$.

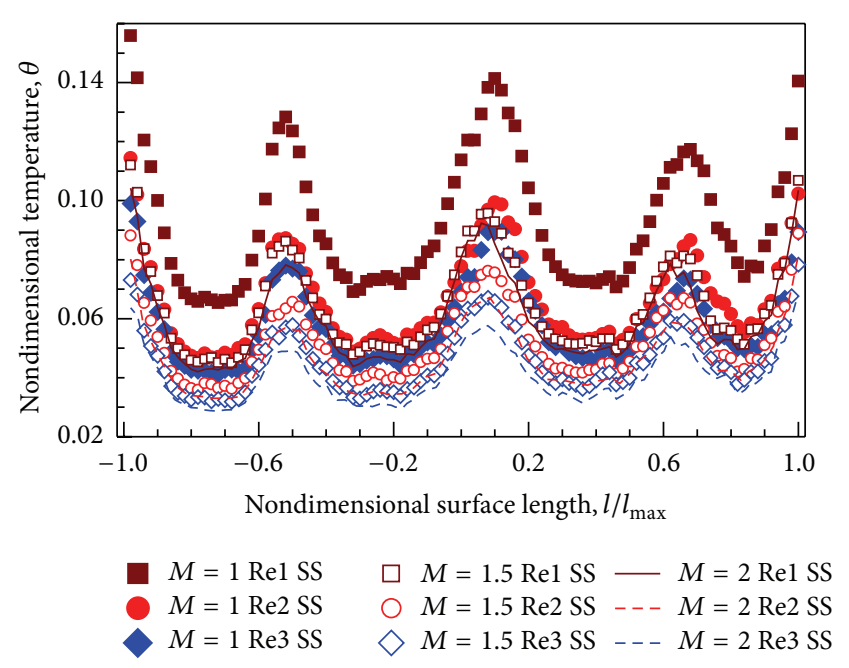

FIGURE 12: Effect of simultaneous variation of both jet Reynolds number and mainstream Reynolds number on nondimensional temperature.

Reynolds number increased (Re2 and Re3) material Perspex attains lower temperature, but same trend is not observed for stainless steel and region of high temperature is found for M1 Re2 and M1 Re3.

The major reason for such peculiar trend is due to the fact that the SS surfaces conduct the hot mainstream temperature more as the mainstream Reynolds number increased and the proportionate increase in jet Reynolds number is not adequate to reduce the temperature. For stainless steel as the blowing ratio increased from 1 to 1.5 , the surface temperature decreases as more green patches are observed. It is also noticed that for the case M2 Rel when the mainstream Reynolds number and jet Reynolds number are minimum the surface temperature is less (more green patches) and as the mainstream Reynolds number increased more increase in inside surface temperature is observed because of conjugate heat transfer effect.

\subsection{Flow Characteristics and Local Variation of Nusselt Number}

3.2.1. Flow Pattern along the Length of the Curved Plate (Spanwise Direction). To show the interaction of jet, along the span of leading edge, planes 1, 2, 3, and 4 are cut across impingement jet rows $1,2,3$, and 4 , respectively, as shown in Figure 15. The jet rows 1 and 3 have 16 numbers of circular jets whereas jet rows 2 and 4 have 15 numbers of jets.

The stream line pattern along with solid leading edge cross section are drawn along the planes 1, 2, 3, and 4 for the case M1 Re1 and presented in Figures 16 and 17, respectively. Each individual jet is named as shown in the stream line and contour plot; for example, the jets present along the jet row 1 are named as $1 \mathrm{~A}$ to $1 \mathrm{P}$. It is observed from the plot that the jet after impinging the internal surface starts spreading in all directions and interact with the adjacent jets to form an up wash region. The up wash movement of the fluid after hitting the top wall forms counter rotating vortex pair as shown in Figure 16. As the jets are arranged in staggered manner minimum cross flow is observed along the spanwise direction. In Figure 16 the conduction on the Perspex surface shows the coolant and mainstream heat penetration on the internal and external surface respectively. For Perspex the coolant penetration nearly uniform in the internal surface 


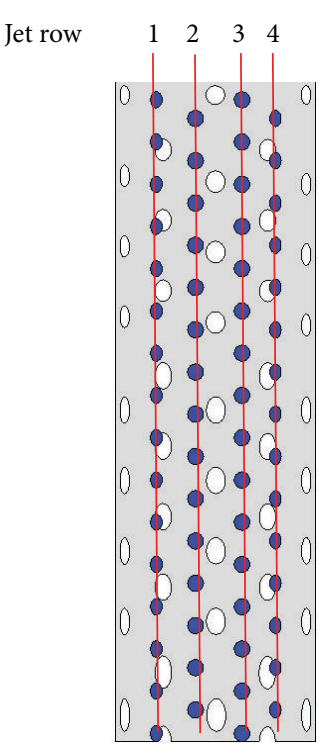

(a)

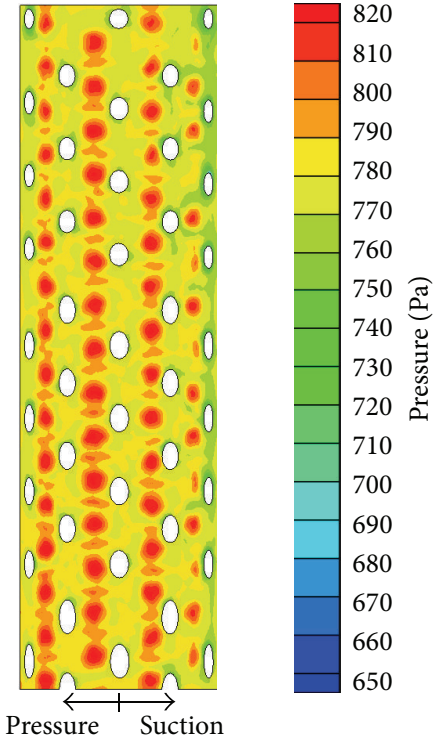

(b)

FIGURE 13: (a) Inner vane wall with four-impingement jet row location. (b) Static pressure contour along the four-jet row.

whereas in the external surface mainstream heat penetration is varying in the four planes. The reason for this variation is due to the differences in orientation of the film holes from hub to tip. The conduction in stainless steel solid leading cross section is shown in Figure 17 which shows that large part of the cross section is affected by the mainstream heat penetration.

3.2.2. Local Nusselt Number along the Length of the Curved Plate (Spanwise Direction). To know the local variation of Nusselt number along the span of the leading edge 4 lines are drawn at the intersection of planes 1,2,3, and 4 and the internal surface. The local variation of Nusselt number along jet rows 1 and 3 are presented for the case M1 Rel in Figure 18. It is observed that the surface Nusselt number attains peak value at the impinging region and secondary peak is observed at the up wash region. The jet rows 1 and 3 each having 16 numbers of jets placed along the same circumferential axis and show similar trend in local Nusselt number distributions. Along jet row 3, between jet $3 \mathrm{O}$ and $3 \mathrm{P}$, a sharp decline in Nusselt number is observed because of absence of counter rotating vortex pair (Figure 17 plane 3) between these jets. The primary reason of change of flow structure is presence of nearby film cooling holes which creates a low pressure region and the predominating direction of flow is changing. The Nusselt number distribution along the jet rows 2 and 4 is presented in Figure 19. The 15 jets present along jet row 2 show least cross flow (Figure 17 plane 2) and formation of counter rotating vortex pair between all the jets which leads to number of primary and secondary peaks along the span of the leading edge. The jet row 4 shows sudden decrease in Nusselt number in between the jets $4 \mathrm{C}-4 \mathrm{D}, 4 \mathrm{D}-4 \mathrm{E}, 4 \mathrm{E}-4 \mathrm{~F}, 4 \mathrm{H}-4 \mathrm{I}$, and $4 \mathrm{~J}-4 \mathrm{~K}$. The flow structure (Figure 17 plane 4 ) along these jets shows only a single vortex pair. The absence of up wash region leads to lower heat transfer coefficient in this region.

\section{Conclusions}

Computational studies are carried out to know the flow and heat transfer characteristic for multiple jet impingement with staggered jets under conjugate boundary condition by considering realistic nozzle guide vane leading edge with effusion holes. Effect of variation of mainstream Reynolds number and jet Reynolds number on internal surface heat transfer coefficient and temperature is investigated. The following conclusions are made from the present computational study.

(1) As long as impinging jet Reynolds number is not varied the surface heat transfer coefficient remains independent of material conductivity and the variation of mainstream Reynolds number.

(2) For a constant coolant jet Reynolds number, the variation of mainstream Reynolds has influence on the internal surface temperature distribution for the high conductivity material but for the low conductivity material it has negligibly small effect for combined impingement and showerhead cooling arrangement of the leading edge.

(3) It is found that for same jet Reynolds number and mainstream Reynolds number, the internal surface (cold side) of higher conductivity material, SS, shows $22 \%$ higher average surface temperature than the lower conductivity material PP when a temperature gradient of $20^{\circ}$ is imposed between mainstream and coolant.

(4) When blowing ratio is increased, there is net increase in surface heat transfer coefficient but this change 


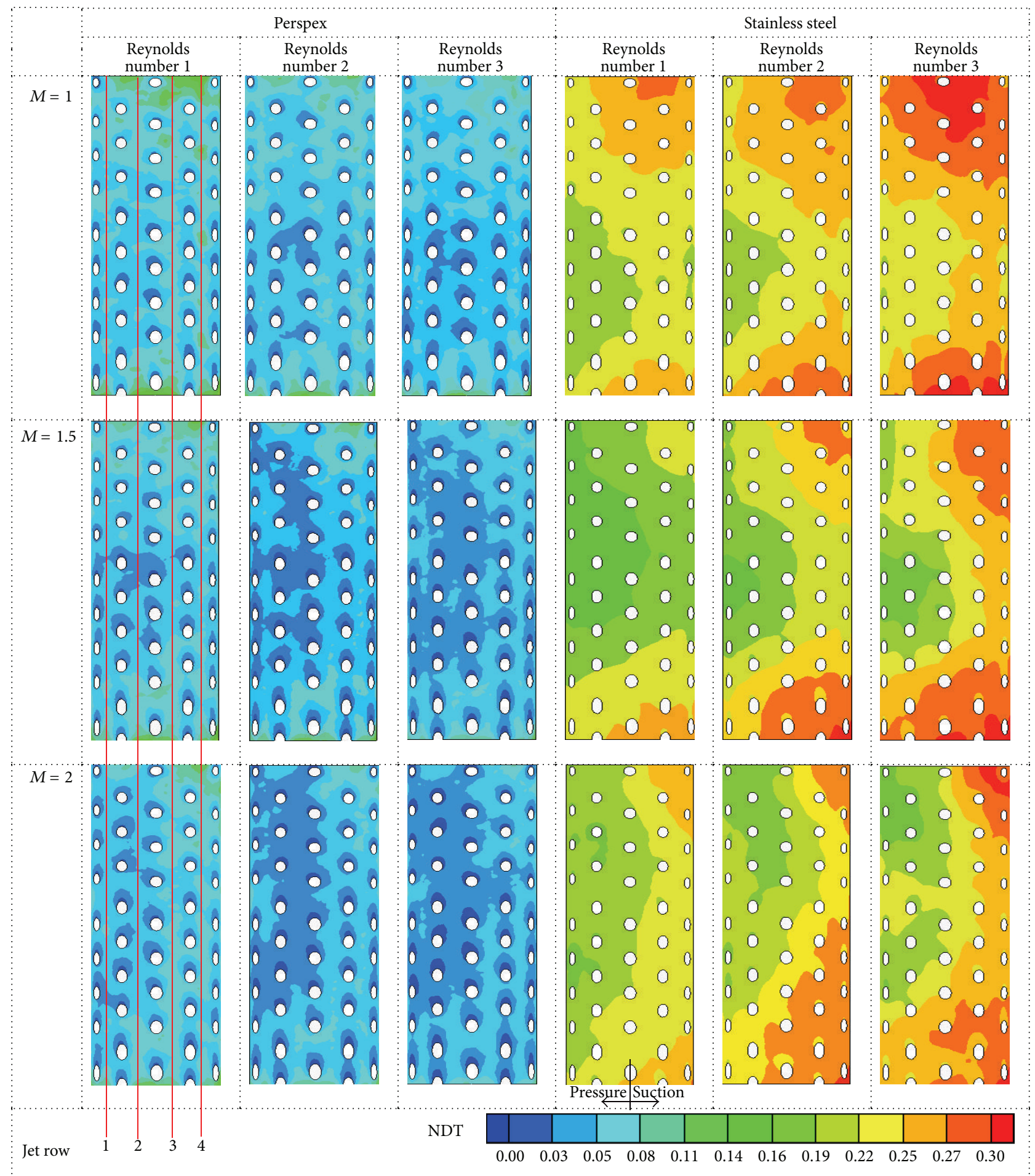

FIGURE 14: Nondimensional temperature contours of Perspex and stainless steel.

is predominately due to the change in jet Reynolds number rather than the mainstream Reynolds number change. It is found that when the jet Reynolds number is increased (by 50\%) there is proportionate increase (by $10 \%$ ) in averaged heat transfer coefficient.
(5) The internal surface temperature distribution for high conducting material largely depends on the external film cooling effectiveness, whereas for low conductivity material jet impingement cooling predominates. This is evident from the fact that keeping mainstream 

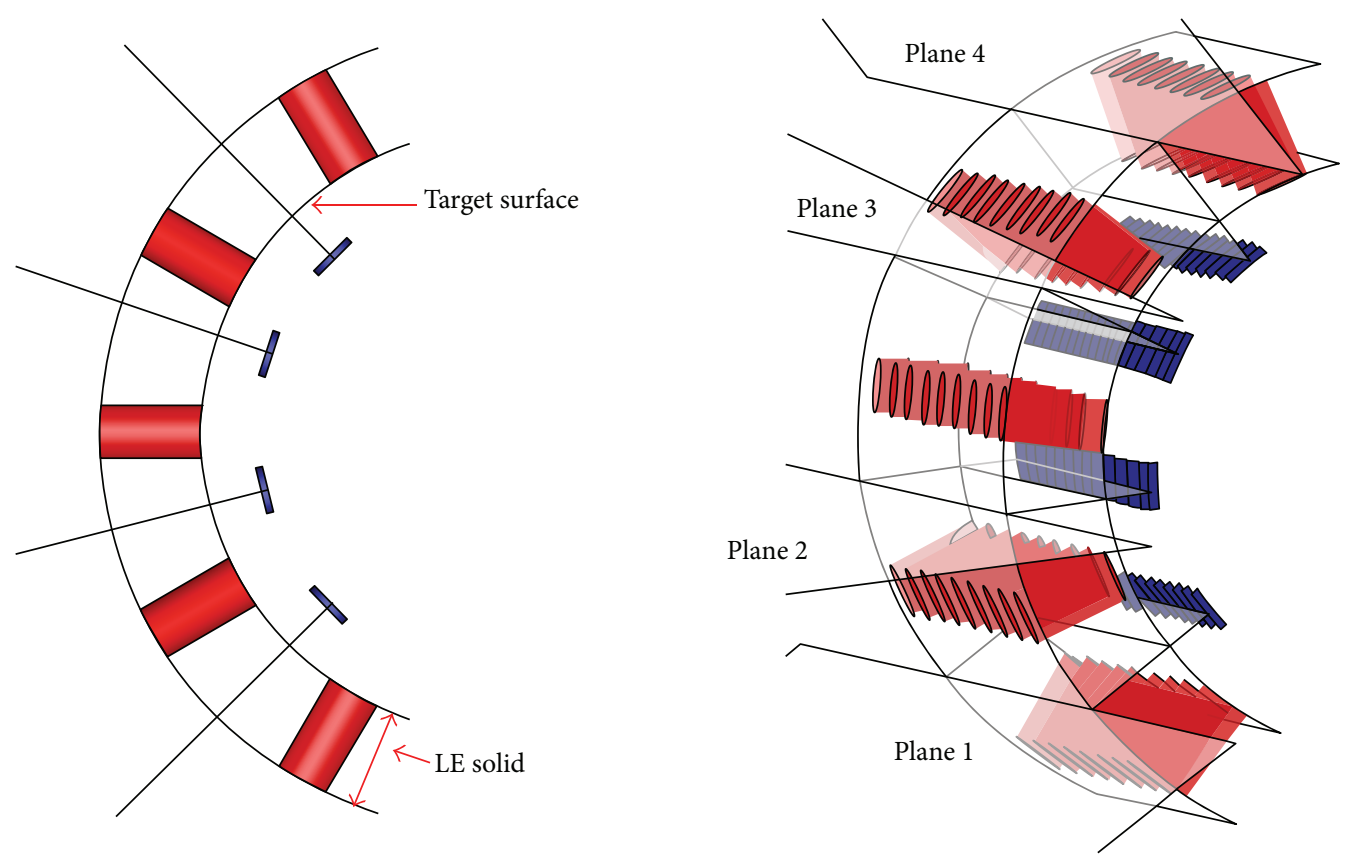

FIGURE 15: Plane cut along jet rows 1, 2, 3, and 4.

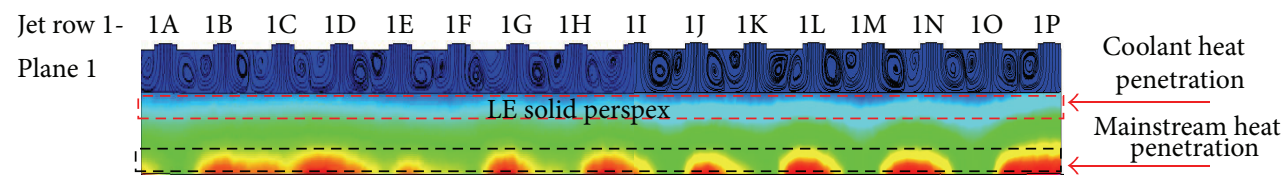

$\begin{array}{llllllllllllllll}\text { Jet row 2- } & 2 \mathrm{~A} & 2 \mathrm{~B} & 2 \mathrm{C} & 2 \mathrm{D} & 2 \mathrm{E} & 2 \mathrm{~F} & 2 \mathrm{G} & 2 \mathrm{H} & 2 \mathrm{I} & 2 \mathrm{~J} & 2 \mathrm{~K} & 2 \mathrm{~L} & 2 \mathrm{M} & 2 \mathrm{~N} & 2 \mathrm{O}\end{array}$

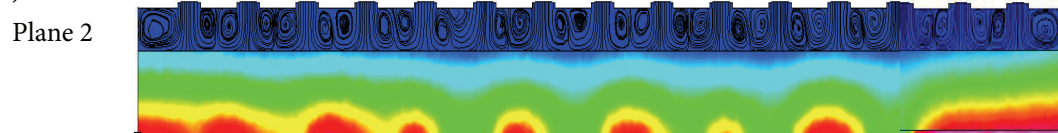

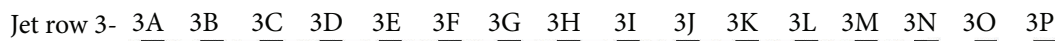
Plane 3

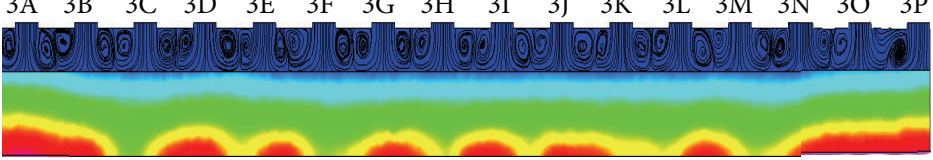

$\begin{array}{llllllllllllllll}\text { Jet row 4- } & 4 \mathrm{~A} & 4 \mathrm{~B} & 4 \mathrm{C} & 4 \mathrm{D} & 4 \mathrm{E} & 4 \mathrm{~F} & 4 \mathrm{G} & 4 \mathrm{H} & 4 \mathrm{I} & 4 \mathrm{~J} & 4 \mathrm{~K} & 4 \mathrm{~L} & 4 \mathrm{M} & 4 \mathrm{~N} & 4 \mathrm{O}\end{array}$
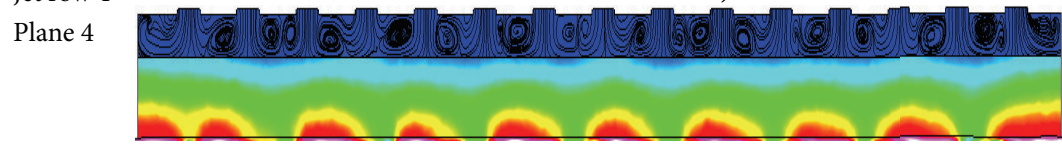

289290291292293294295296297298298299300301302303304305306307

Temperature

FIGURE 16: Stream line pattern along with temperature contour along the planes 1, 2, 3, and 4(SS).

Reynolds number constant when the jet Reynolds number increased by $50 \%$ (M1 and M1.5) the average internal nondimensional temperature shows decrease by $11 \%$ but between blowing ratios M1.5 Rel and M2 Rel though the coolant jet Reynolds number is increased and average internal surface temperature is increased by $8 \%$. it is observed that among all the cases the M1.5 Rel gives optimum surface temperature distribution for moderate jet velocity $(12.7 \mathrm{~m} / \mathrm{s})$.

(6) For the higher conductivity material (SS) It is observed that two different blowing ratios (M2 Re2 


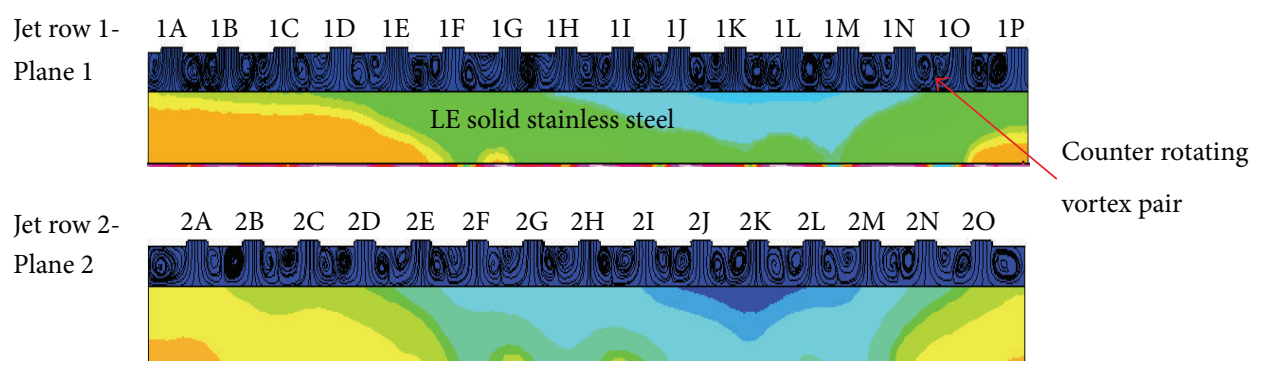

$\begin{array}{lllllllllllllllll}\text { Jet row } 3- & 3 \mathrm{~A} & 3 \mathrm{~B} & 3 \mathrm{C} & 3 \mathrm{D} & 3 \mathrm{E} & 3 \mathrm{~F} & 3 \mathrm{G} & 3 \mathrm{H} & 3 \mathrm{I} & 3 \mathrm{~J} & 3 \mathrm{~K} & 3 \mathrm{~L} & 3 \mathrm{M} & 3 \mathrm{~N} & 3 \mathrm{O} & 3 \mathrm{P}\end{array}$ Plane 3

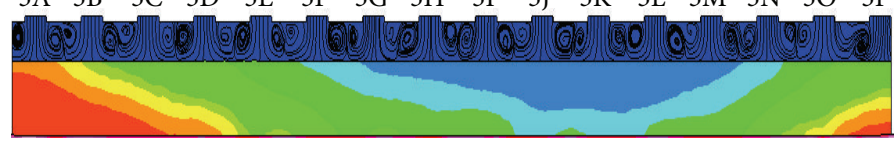

Jet row 4-

$\begin{array}{lllllllllllllll}4 \mathrm{~A} & 4 \mathrm{~B} & 4 \mathrm{C} & 4 \mathrm{D} & 4 \mathrm{E} & 4 \mathrm{~F} & 4 \mathrm{G} & 4 \mathrm{H} & 4 \mathrm{I} & 4 \mathrm{~J} & 4 \mathrm{~K} & 4 \mathrm{~L} & 4 \mathrm{M} & 4 \mathrm{~N} & 4 \mathrm{O}\end{array}$

Plane 4

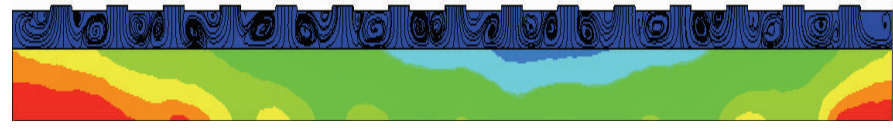

289290291292293294295296297298298299300301302303304305306307

Temperature

FIGURE 17: Stream line pattern along with temperature contour along the planes 1, 2, 3, and 4(SS).

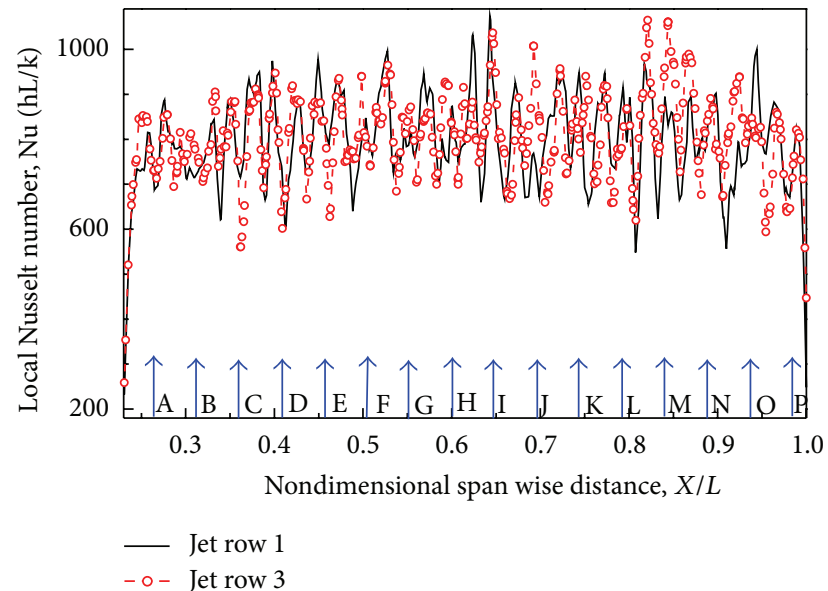

FIgURE 18: Local Nusselt number variation along the span of the vane for jet rows 1 and 3 .

and M1.5 Re3) give the similar averaged temperature distribution because mainstream velocity is decreased by $33 \%$ but the proportionate decrease in jet velocity is less $(11 \%)$.

(7) The staggered jets arrangements of jets leads to minimum cross flow along the spanwise direction which leads to maximum local heat transfer coefficient. Primary peak in Nusselt number is observed at the jet impinging region where as the secondary peak of local Nusselt number is observed at the up wash region form between jets. The region below jet row 4

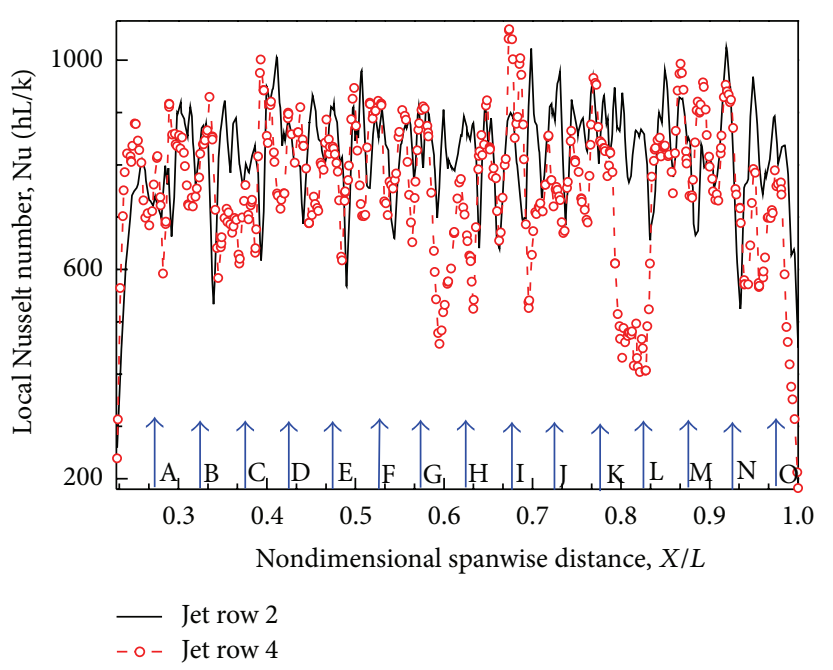

Figure 19: Local Nusselt number variation along the span of the vane for jet rows 2 and 4 .

shows minimum average Nusselt number because of low pressure region created by the film holes present at the suction side.

\section{Nomenclature}

Ch: Chord [m]

$\mathrm{C}_{p}$ : Coefficient of pressure $\left[\left(P_{s}-P_{m}\right) / 0.5 \rho V^{2}\right]$

$d$ : Jet diameter $[\mathrm{m}]$

$D$ : Effusion hole diameter [m]

$h$ : Heat transfer coefficient $\left[\mathrm{W} / \mathrm{m}^{2} \mathrm{~K}\right]$ 


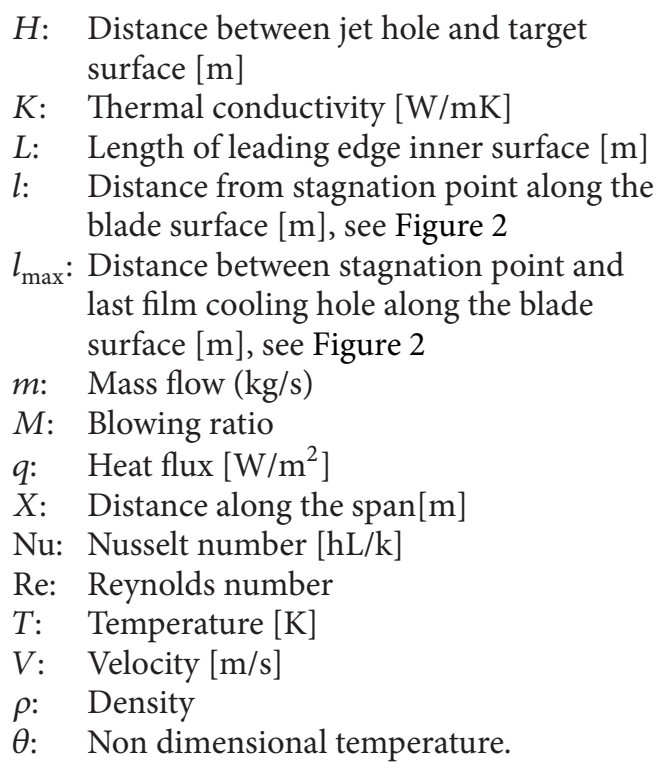

\section{Subscripts}

amb: Ambient

aw: Adiabatic wall

C: Coolant

$f$ : Fluid

htc: Heat transfer coefficient

$m$ : Mainstream

min: Minimum

$w$ : Wall

$s: \quad$ Solid

TLC: Thermochromic liquid crystal.

\section{Conflict of Interests}

The authors declare that there is no conflict of interests regarding the publication of this paper.

\section{Acknowledgment}

The authors would like to thank GTRE Bangalore for financial support.

\section{References}

[1] B. R. Hollworth and L. Dagan, "Arrays of Impinging Jets with spent fluid removal through vent holes on the target surface. Part I. Average Heat Transfer," ASME Journal of Engineering for Power, vol. 102, no. 4, pp. 994-999, 1980.

[2] B. R. Hollworth, G. Lehmann, and J. Rosiczkowski, "Arrays of Impinging Jets with spent fluid removal through vent holes on the target surface-part II: local heat transfer," Journal of Engineering for Power, vol. 105, no. 2, pp. 393-402, 1983.

[3] H. H. Cho and D. H. Rhee, "Local heat/mass transfer measurement on the effusion plate in impingement/effusion cooling systems," Journal of Turbomachinery, vol. 123, no. 3, pp. 601-608, 2001.
[4] S. V. Ekkad, Y. Huang, and J.-C. Han, "Impingement heat transfer on a target plate with film cooling holes," AIAA Journal of Thermophysics and Heat Transfer, vol. 13, no. 4, pp. 522-528, 1999.

[5] D. E. Metzger, T. Yamashita, and C. W. Jenkins, "Impingement cooling of concave surfaces with lines of circular air jets," Journal of Engineering for Gas Turbines and Power, vol. 91, no. 3, pp. 149-155, July 1969.

[6] H. Thomann, "Effect of stream wise wall curvature on heat transfer in a turbulent boundary layer," Journal of Fluid Mechanics, vol. 33, no. 2, pp. 283-292, 1968.

[7] W. Tabakoff and W. Clevenger, "Gas turbine blade heat transfer augmentation by impingement of air jets having various configurations," ASME Journal of Engineering for Power, vol. 94, no. 1, pp. 51-60, 1972.

[8] R. S. Bunker and D. E. Metzger, "Local heat transfer in internally cooled turbine airfoil leading edge regions. Part I. Impingement cooling without film coolant extraction," ASME Journal of Turbomachinery, vol. 112, no. 3, pp. 451-458, 1990.

[9] D. E. Metzger and R. S. Bunker, "Local heat transfer in internally cooled turbine airfoil leading edge regions. Part II. Impingement cooling with film coolant extraction," ASME Journal of Engineering for Power, vol. 112, no. 3, pp. 459-467, 1990.

[10] B. V. N. Ramakumar and B. V. S. S. S. Prasad, "Computational investigation of flow and heat transfer for a row of circular jets impinging on a concave surface," in ASME Turbo Expo, pp. 657667, paper no. GT2006-90851.

[11] B. V. N. Ramakumar and B. V. S. S. S. Prasad, "Computational flow and heat transfer of a row of circular jets impinging on a concave surface," Heat and Mass Transfer, vol. 44, no. 6, pp. 667678, 2008.

[12] M. A. Kumar and B. V. S. S. S. Prasad, "Computational investigations of impingement heat transfer on an effused concave surface," in Proceedings of the 11th Asian International Conference on Fluid Machinery (AICFM '11), November 2011.

[13] R. K. Panda and B. V. S. S. S. Prasad, "Conjugate heat transfer from a flat plate with combined impingement and film cooling," ASME Paper GT2012-68830, 2012.

[14] Y. Li, R. Kan, R. Jing, and H. Jiang, "Effect of film cooling arrangement on impingement heat transfer on turbine blade leading edge," ASME Paper no. GT2013-95261, 2013.

[15] C. N. Jordan, C. A. Elston, L. M. Wright, and D. C. Crites, "Leading edge impingement with racetrack shaped jets and varying inlet supply conditions," ASME Paper no. GT201394611, 2013.

[16] A. B. Mehendale and J. C. Han, "Reynolds number effect on leading edge film effectiveness and heat transfer coefficient," International Journal of Heat and Mass Transfer, vol. 36, no. 15, pp. 3723-3730, 1993.

[17] J. D. Heidmann, A. J. Kassab, E. A. Divo, F. Rodriguez, and E. Steinthorsson, "Conjugate heat transfer effects on a realistic film-cooled turbine vane," in Proceedings of the ASME Turbo Expo, pp. 361-371, Atlanta, Ga, USA, June 2003.

[18] S. C. Lau, L. E. Ong, and J. C. Han, "Conjugate heat transfer in channels with internal longitudinal fins," Journal of Thermophysics and Heat Transfer, vol. 3, no. 3, pp. 303-308, 1989.

[19] Z. Gao, H. Yang, L. M. Wright, and J.-C. Han, "Conjugate prediction of leading edge film cooling and heat transfer," in 
Proceedings of the 11th International Symposium on Transport Phenomena and Dynamics of Rotating Machinery (ISROMAC '11), pp. 181-189, Honolulu, Hawaii, USA, February-March 2006.

[20] F. Montomoli, M. Massini, H. Yang, and J. C. Han, "The benefit of high-conductivity materials in film cooled turbine nozzles," International Journal of Heat and Fluid Flow, vol. 34, pp. 107-116, 2012. 

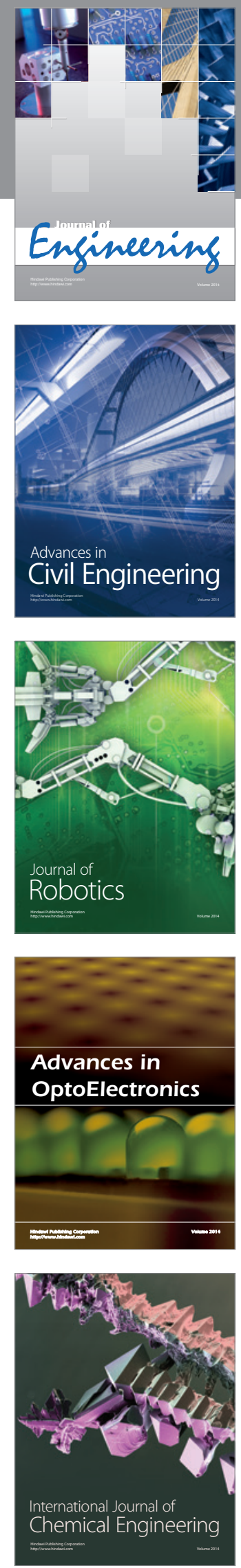

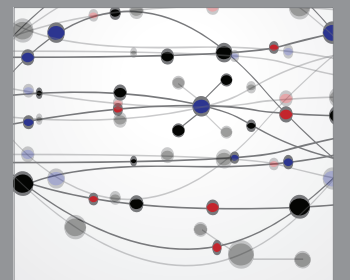

The Scientific World Journal
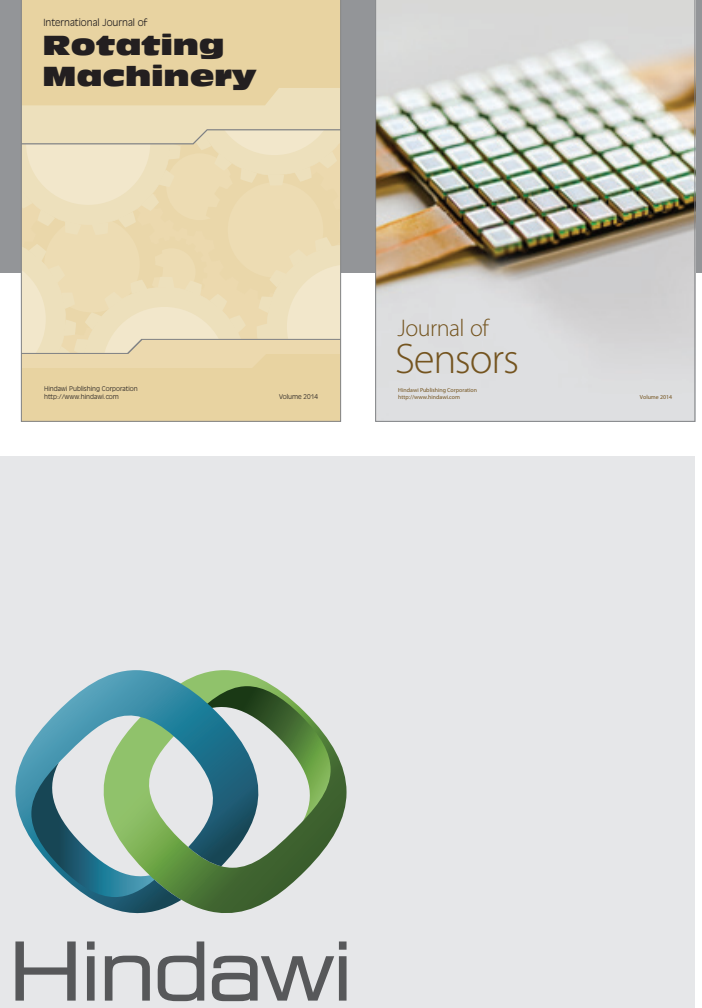

Submit your manuscripts at http://www.hindawi.com
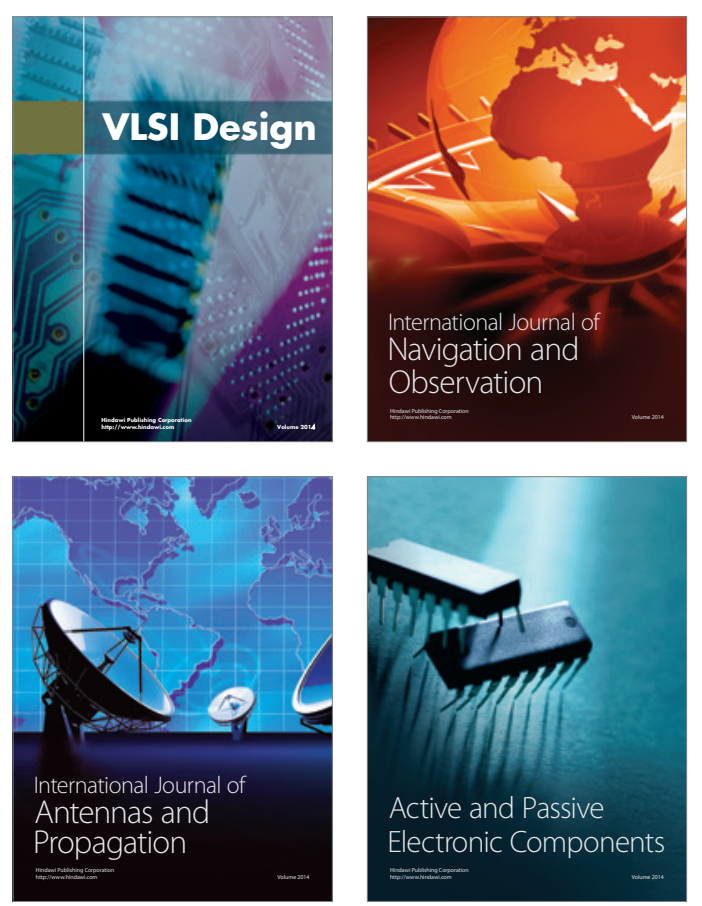
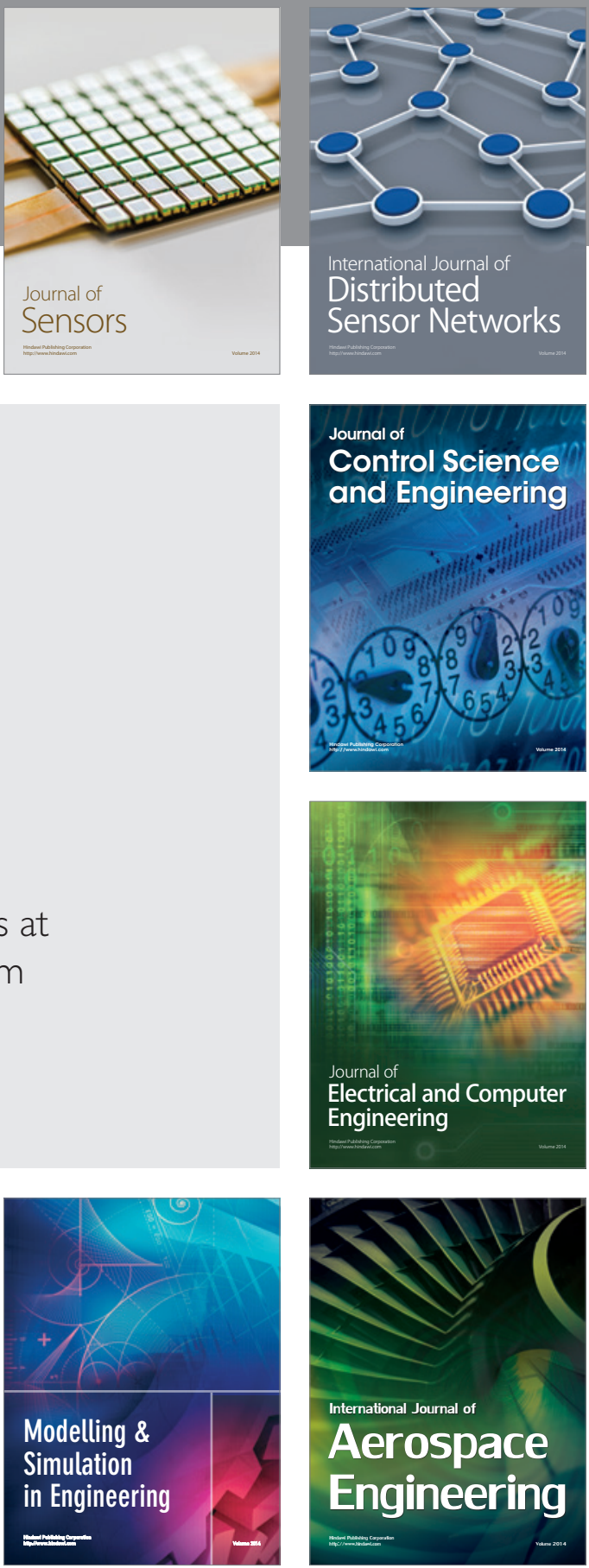

Journal of

Control Science

and Engineering
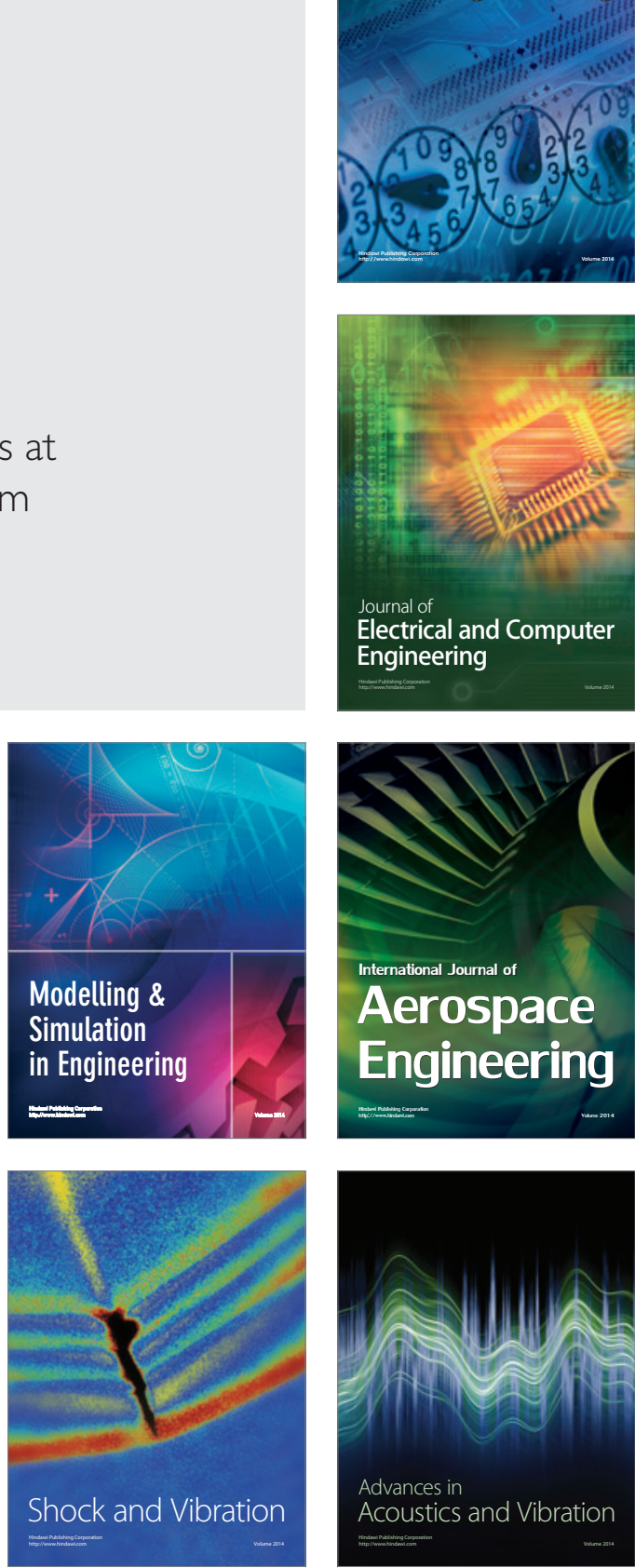